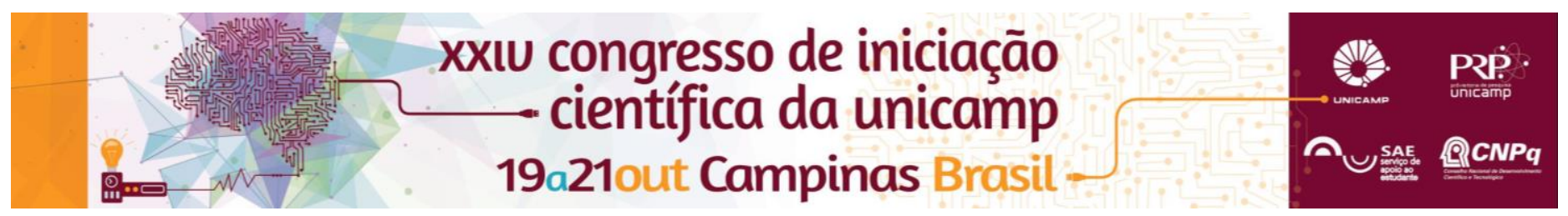

\title{
Ligas de Magnésio-Níquel para Armazenagem de Hidrogênio Processadas por Laminação a Frio
}

\section{Andressa P. Falcon*, Ricardo Floriano}

\section{Resumo}

A armazenamento de hidrogênio é um dos gargalos para tornar viável a sua aplicação como fonte de energia alternativa. Neste estudo, amostras de $\mathrm{Mg}$ contendo $21 \%$ em peso de $\mathrm{Ni}$ foram processadas por a laminação a frio seguida de moagem mecânica (MM) incluindo etapas de tratamentos térmicos (TT). As amostras foram caracterizadas por difração de raios-X e microscopia eletrônica de varredura. Resultados preliminares mostraram uma intensa inserção de defeitos e um refinamento da microestrutura até a escala nanométrica. As amostras que passaram por períodos maiores de TT apresentaram uma estrutura mais refinada. Medidas cinéticas de ativação, absorção e dessorção de hidrogênio estão em andamento.

\section{Palavras-chave:}

Armazenagem de hidrogênio, liga Mg-Ni, laminação a frio.

\section{Introdução}

$\mathrm{O} \mathrm{MgH}_{2}$ destaca-se por ter capacidade reversível de armazenamento de hidrogênio de 7,6\% em massa, boa reversibilidade e estabilidade cíclica, além do baixo custo. Entretanto, ainda há limitações para o uso comercial em larga escala deste hidreto, como, por exemplo, são necessárias altas temperaturas e pressões elevadas para a realização do processo de ativação [1].

Avanços consideráveis foram obtidos nas últimas décadas por meio do uso de materiais nanoestruturados a base de $\mathrm{Mg}$ (em pó) aliada a inserção de aditivos e o uso de outras ligas [1]. Neste trabalho, ligas de $\mathrm{Mg}$ contendo $21 \%$ em peso de $\mathrm{Ni}$ foram processadas por laminação a frio seguidas de etapas curtas de MM. A influência de rotinas de tratamento térmico (TT) antes e após a laminação frio também foram investigadas. Por fim, espera-se definir qual a melhor rota de processamento de acordo com a análise da microestrutura final obtida e da avaliação das propriedades de armazenagem de hidrogênio.

\section{Resultados e Discussão}

As amostras de estudo e a descrição da rota de processamento empregada são apresentadas na Tabela 1. Foi adicionado $5 \%$ em massa de $\mathrm{MgH}_{2}$ em excesso durante a etapa de MAE para fins de ativação. .

Tabela 1. Amostras de estudo e rota de processamento empregada.

\begin{tabular}{|c|c|}
\hline Amostras de Estudo & Descrição da Rota \\
\hline 1 & $\mathrm{TT}(4 \mathrm{~h}) \rightarrow \mathrm{CR}(17$ passes $) \rightarrow \mathrm{MAE}(10 \mathrm{~min})$ \\
\hline 2 & $\mathrm{TT}(12 \mathrm{~h}) \rightarrow \mathrm{CR}(17$ passes $) \rightarrow \mathrm{MAE}(10 \mathrm{~min})$ \\
\hline 3 & $\mathrm{CR}(17$ passes $) \rightarrow \mathrm{TT}(4 \mathrm{~h}) \rightarrow \mathrm{MAE}(10 \mathrm{~min})$ \\
\hline 4 & $\mathrm{CR}(17$ passes $) \rightarrow \mathrm{MAE}(10 \mathrm{~min})$ \\
\hline 5 & $\mathrm{CR}(17$ passes $) \rightarrow \mathrm{TT}(12 \mathrm{~h}) \rightarrow \mathrm{MAE}(10 \mathrm{~min})$ \\
\hline
\end{tabular}

Os padrões de DRX revelaram a presença de quatro fases cristalográficas, identificadas como: $\mathrm{Mg}, \mathrm{Ni}, \mathrm{MgH}_{2}$, além da presença da fase espúria de $\mathrm{MgO}$. A presença das fases: $\mathrm{Mg}, \mathrm{Ni}$ e $\mathrm{MgH}_{2}$ são esperadas, pois, tratam-se da mistura inicial. Já a formação de $\mathrm{MgO}$ (verificada em outros estudos) pode ter ocorrido devido ao processo inicial de moagem, que foi realizada sob ar e também às condições favoráveis ao aparecimento de óxido, como a elevação de temperatura e o contato do magnésio sólido com o gás oxigênio durante a laminação. Uma orientação preferencial decorrente do processo de laminação, na direção dos planos (002) para o Mg foi observado em todas as amostras de estudo. O tamanho médio de cristalito calculado em todas as amostras foi de $46 \mathrm{~nm}$ pelo método de Scherrer e $63 \mathrm{~nm}$ pelo método de Williamson-Hall.

As imagens de MEV (contraste de composição) das amostras de estudo revelam uma matriz rica em $\mathrm{Mg}$, em maior quantidade, com uma boa dispersão da fase de Níquel. Além disso, comparando os períodos de TT, podese notar que as amostras que passaram por TT de $12 \mathrm{~h}$ possuem uma distribuição de partículas de $\mathrm{Mg}$ muito mais refinada do que as amostras que passaram por TT de $4 \mathrm{~h}$. Isto pode estar relacionado com um aumento no grau de fragilidade das amostras com o TT prolongado, o que facilitaria a quebra das partículas durante a laminação seguida moagem mecânica.

\section{Conclusões}

Com as etapas realizadas até então, pode-se comprovar a efetividade na inserção de defeitos e deformação das partículas, por meio do processamento por laminação a frio seguida de MM. Além disso, a influência que o TT tem no refinamento destas partículas. Espera-se verificar os efeitos destes processamentos com as análises de propriedades cinéticas de absorção e dessorção de hidrogênio e a capacidade de $\mathrm{H}_{2}$ em massa que estão em andamento.

\section{Agradecimentos}

Ao meu orientador Prof. Dr Ricardo Floriano pela oportunidade de realização deste trabalho, por todo auxílio e incentivo no decorrer da pesquisa.

Ao PIBIC/CNPQ, pela bolsa de iniciação científica.

À Faculdade de Ciências Aplicadas, FCA, da Unicamp e ao Departamento de Engenharia de Materiais, DEMA, da UFSCar, por todo o suporte com os equipamentos utilizados.

${ }^{1}$ D. M. Grant et.al, Review of magnesium hydride-based materials: development and optimisation, Applied Physics A, v. 122, 2016. 